\title{
Novel method for determining DDT in vapour and particulate phases within contaminated indoor air in a malaria area of South
}

\author{
Africa \\ Yvette Naudé* and Egmont R. Rohwer \\ Department of Chemistry, University of Pretoria, Private Bag X20, Hatfield 0028, Pretoria, South \\ Africa
}

\section{ABSTRACT}

The organochlorine insecticide DDT (1,1,1-trichloro-2,2-bis $(p$ chlorophenyl)ethane) is still used for malaria vector control in certain areas of South Africa. The strict Stockholm Convention on Persistent Organic Pollutants (POPs) allows spraying on the inside of traditional dwellings with DDT. In rural villages contaminated dust presents an additional pathway for exposure to DDT. We present a new method for the determination of DDT in indoor air where separate vapour and particulate samples are collected in a single step with a denuder configuration of a multi-channel open tubular silicone rubber (polydimethylsiloxane (PDMS)) trap combined with a micro quartz fibre filter. The multi-channel PDMS trap section of the denuder concentrates vapour phase insecticide whereas particle associated insecticide is transferred downstream where it is collected on a micro-fibre filter followed by a second multi-channel PDMS trap to capture the blow-off from the filter. The multi-channel PDMS trap and filter combination are designed to fit a commercial thermal desorber for direct introduction of samples into a GC-MS. The technique is 
solvent-free. Analyte extraction and sample clean-up is not required. Two fractions, vapour phase and particulate phase $p, p^{\prime}-\mathrm{DDT}, o, p^{\prime}-\mathrm{DDT} ; p, p^{\prime}-\mathrm{DDD}, o, p^{\prime}-\mathrm{DDD} ; p, p^{\prime}-$ DDE and $o, p$ '-DDE in $4 \mathrm{~L}$ contaminated indoor air, were each quantitatively analysed by GC-MS using isotopically labeled ring substituted ${ }^{13} \mathrm{C}_{12}-p, p$ '-DDT as an internal standard. Limits of detection were $0.07-0.35 \mathrm{ng} \mathrm{m}^{-3}$ for $p, p^{\prime}-\mathrm{DDT}, o, p^{\prime}-\mathrm{DDT}, p, p^{\prime}-$ DDD, $o, p^{\prime}-\mathrm{DDD}, p, p^{\prime}-\mathrm{DDE}$ and $o, p^{\prime}-\mathrm{DDE}$. Ratios of airborne $p, p^{\prime}-\mathrm{DDD} / p, p^{\prime}-\mathrm{DDT}$ and of $o, p^{\prime}-\mathrm{DDT} / p, p^{\prime}-\mathrm{DDT}$ are unusual and do not match the ideal certified ingredient composition required of commercial DDT. Results suggest that the DDT products used for indoor residual spraying (IRS) prior to, and during 2007, may have been compromised with regards to insecticidal efficacy, demonstrating the power of this new environmental forensics tool.

Keywords: Airborne contaminants; Multi-channel open tubular trap;

Polydimethylsiloxane (PDMS) sorptive extraction; Denuder; Environmental forensics; Persistent organic pollutants (POPs)

*Corresponding author. Tel.: +27 12420 2517; fax: +27 124204687.

E-mail address: yvette.naude@up.ac.za 


\section{Introduction}

DDT (1,1,1-trichloro-2,2-bis( $p$-chlorophenyl)ethane), an organochlorine insecticide, is still used for malaria vector control in risk regions in South Africa. The strict Stockholm Convention on Persistent Organic Pollutants (POPs) permits Indoor Residual Spray (IRS) of traditional dwellings with DDT. IRS with DDT decreased the number of deaths caused by malaria in South Africa by $65 \%$ and decreased the number of confirmed malaria cases by $83 \%$ [1]. At present there are no effective insecticides that could replace DDT [2].

Semivolatile organic compounds are present in air, either adsorbed onto dust particles or as free gas phase molecules $[3,4]$. Exposure may be via inhalation of gas and particulate phase compounds, or by ingestion. Once larger sized contaminated particles are inhaled it deposits in the upper respiratory tract and is swallowed [5]. In rural villages contaminated dust presents a pathway for exposure to DDT, especially when the dust is disturbed during domestic activities in and around traditional dwellings. Conventional high volume collection systems for POPs are polyurethane foam (PUF) $[5,6]$ or polymeric resin (XAD-2 or XAD-4) $[6,7]$. PUF samples total air, i.e., vapour and particulate phases, and does not distinguish between contributions from each phase. In order to sample both phases, glass fibre or quartz filters are placed upstream of the solid sorbents to first collect particulate phase pesticides while vapour phase is trapped onto the sorbent [6,8-14]. After sampling the materials are separately extracted by Soxhlet extraction (16-36 h) with large amounts of solvents, or by sonication $[7,9,15]$, concentrated by Kuderna Danish or rotary evaporation, followed by nitrogen gas blow-down [6,8-14]. Microlitre amounts are injected for analysis. This approach is quite successful but 
involves many preparation steps, large amounts of solvents, loss of analyte, introduction of interferences and potential errors. Moreover, sensitivity limitations are associated with injection of only a fraction of the final $100 \mu \mathrm{L}$ to $1 \mathrm{~mL}$ concentrate [16].

Particulate phase organic compounds may be underestimated by the above procedure due to loss of the reversibly adsorbed molecules on the filter - the so called blow-off effect $[8,10,17]$. Adsorption of the gas phase fraction onto particles already collected, or by the filter itself, may also occur $[8,11]$. Diffusion denuder samplers were developed to overcome the problems associated with filter+PUF samplers [11]. By placing a filter after the low-flow denuder sampler to collect the particles, the collection of gas and particulate phases is reversed from the conventional high-volume sampler [17]. Due to a difference in vapour and particle diffusivities, diffusion denuders first separate the vapour phase from the particulate phase [11]. Traditional diffusion denuders include annular, multi-capillary and honeycomb designs that are coated with various sorbents including silicone grease/gum, XAD, Tenax, Florisil [11]. Denuder fabrication procedures are cumbersome. Denuder materials are solvent extracted or thermally desorbed [11]. The use of adsorptive sorbents in combination with thermal desorption to analyse high molecular-weight compounds is problematic due to incomplete desorption [16]. Sample trapping using polydimethylsiloxane (PDMS) performs well in combination with thermal desorption [16]. In contrast with adsorptive concentration, PDMS functions as a hydrophobic solvent for the analytes $[16,18]$.

Multi-channel configuration devices designed for air pollution studies have been utilised by Lane et al. [19] who coated a collection of glass tubes on the inside and on the outside with stationary phase, and by Kriegler and Hites [20] who used a 
bundle of fused silica tubes cut from a single DB-1 capillary GC column. Practical limitations were complicated instrumental arrangements and high pressure drops due to the longer length of the traps $(25-60 \mathrm{~cm})$. Ortner and Rohwer [21] constructed shorter length $(10.5-12.5 \mathrm{~cm})$ thick film silicone rubber (PDMS) traps in a multi-channel configuration to concentrate semi-volatile organic air pollutants. The traps were desorbed in an inlet similar to a programmable temperature vaporisation (PTV) injector. Multi-channel PDMS traps and thermal desorption in a commercial system were successfully used for monitoring of atmospheric polycyclic aromatic hydrocarbons (PAHs) [18, 22-24]. Advantages of the multi-channel PDMS trap over commercial packed or coated sorptive devices are its open tubular structure and low pressure drop associated with laminar multi-channel flow $[21,22,24]$. Compared to multi-channel traps consisting of a bundle of GC capillary columns which contain nonsorptive outer coatings, both the inside and the outside of the multi-channel silicone rubber trap provide sorptive surfaces.

Considerations for transporting of equipment and sampling in rural areas of South Africa are that electricity is not freely available, travel distances from rural areas to city laboratories are considerable, road conditions are rough both on and off- road, and cargo space is often limited. Simple, small, battery operated, off-line, field monitoring equipment is therefore preferable to bulky, expensive, conventional high flow PUF based equipment. We describe a new solventless method for the determination of DDT in indoor air: vapour and particulate phases are collected separately in a single step, with a low pressure-drop denuder configuration of multichannel open tubular PDMS traps combined with a micro quartz fibre filter. Air is drawn with a small and simple, off-line, battery-operated field sampler at a low air flow sampling rate and short collection time. 


\section{Materials and methods}

\subsection{Chemical standards}

A certified organochlorine pesticides standard mixture ( $p, p^{\prime}-\mathrm{DDT}, o, p^{\prime}-\mathrm{DDT}$; $p, p^{\prime}-\mathrm{DDD}, o, p^{\prime}-\mathrm{DDD} ; p, p^{\prime}-\mathrm{DDE}$ and $o, p^{\prime}-\mathrm{DDE}$, purity $\geq 97 \%$ ) and a certified inlet degradation mixture ( $p, p^{\prime}-\mathrm{DDT}$ and Endrin, purity $\geq 98 \%$,) were purchased from Sigma-Aldrich (Pty) Ltd. Kempton Park, South Africa. Solvents used were of analytical grade. The standard stock solution was diluted in hexane (Merck Chemicals (Pty) Ltd., South Africa) to give calibration standard solutions ranging from $0.5 \mathrm{pg} \mu \mathrm{L}^{-1}$ to $5 \mathrm{ng} \mu \mathrm{L}^{-1}$. The inlet degradation solution ( $\left.p, p^{\prime}-\mathrm{DDT}\right)$ was diluted in hexane to give a concentration of $1 \mathrm{ng} \mathrm{\mu L}^{-1}$. An isotope-labeled internal standard, ring substituted ${ }^{13} \mathrm{C}_{12}-p, p^{\prime}$-DDT (purity 99\%), was diluted in hexane to give a concentration of $1 \mathrm{ng} \mathrm{LL}^{-1}$ (Cambridge Isotope Laboratories, Inc. imported by Industrial Analytical (Pty) Ltd., South Africa). Technical DDT powders used in one of the IRS programmes, were kindly donated by FDA Laboratories, Brooklyn, South Africa. The technical DDT powders were each first dissolved in acetone (Merck Chemicals (Pty) Ltd., South Africa) followed by dilution in hexane to give a concentration of $13 \mathrm{ng} \mathrm{LL}^{-1}$. Working standards of the technical DDT solutions were prepared by dilution in hexane to give a concentration of $1.3 \mathrm{ng} \mu \mathrm{L}^{-1}$. 


\subsection{Denuder sampling device}

Multi-channel open tubular PDMS traps containing $0.4 \pm 0.02 \mathrm{~g}$ silicone were prepared based on a technique described by Ortner and Rohwer [21]. The PDMS trap, providing a sample enrichment volume of $600 \mu \mathrm{L}$, was designed to fit a commercial thermal desorber system (TDS) available from Gerstel ${ }^{\mathrm{TM}}$. Twenty two silicone elastomer medical grade tubes $\left(0.64 \mathrm{~mm}\right.$ OD $\times 0.30 \mathrm{~mm} \mathrm{ID,} \mathrm{SIL-TEC}{ }^{\mathrm{TM}}$, Technical Products, Georgia, United States of America) were arranged, in parallel, in a $17.8 \mathrm{~cm}$ long glass desorption tube (4 mm ID, $6 \mathrm{~mm}$ OD)(Fig. 1). The PDMS trap inside the desorption tube was $55 \mathrm{~mm}$ long (Fig. 1).

Micro quartz fibre filters, $5 \mathrm{~mm}$ OD, were punched from Ederol Quartz Microfibre sheets $(0.43 \mathrm{~mm}$ thickness, pore size $0.3 \mu \mathrm{m}$, grade T293) from Munktell \& Filtrak GmbH Bärenstein, Germany. Denuder sampling devices were assembled by placing a micro quartz fibre filter flush between two multi-channel PDMS traps. The multi-channel PDMS traps and in-line filter were held firmly in place with a polytetrafluoroethylene (PTFE) sleeve (Fig. 1). The ends of the glass denuder were capped with glass stoppers during storage. The glass stoppers were secured with tight-fitting PTFE sleeves. The trapped analytes inside the multi-channel PDMS trap and quartz micro-fibre filter of the denuder are not directly exposed to the PTFE sleeves, thereby preventing potential adsorption of analytes onto the Teflon. 


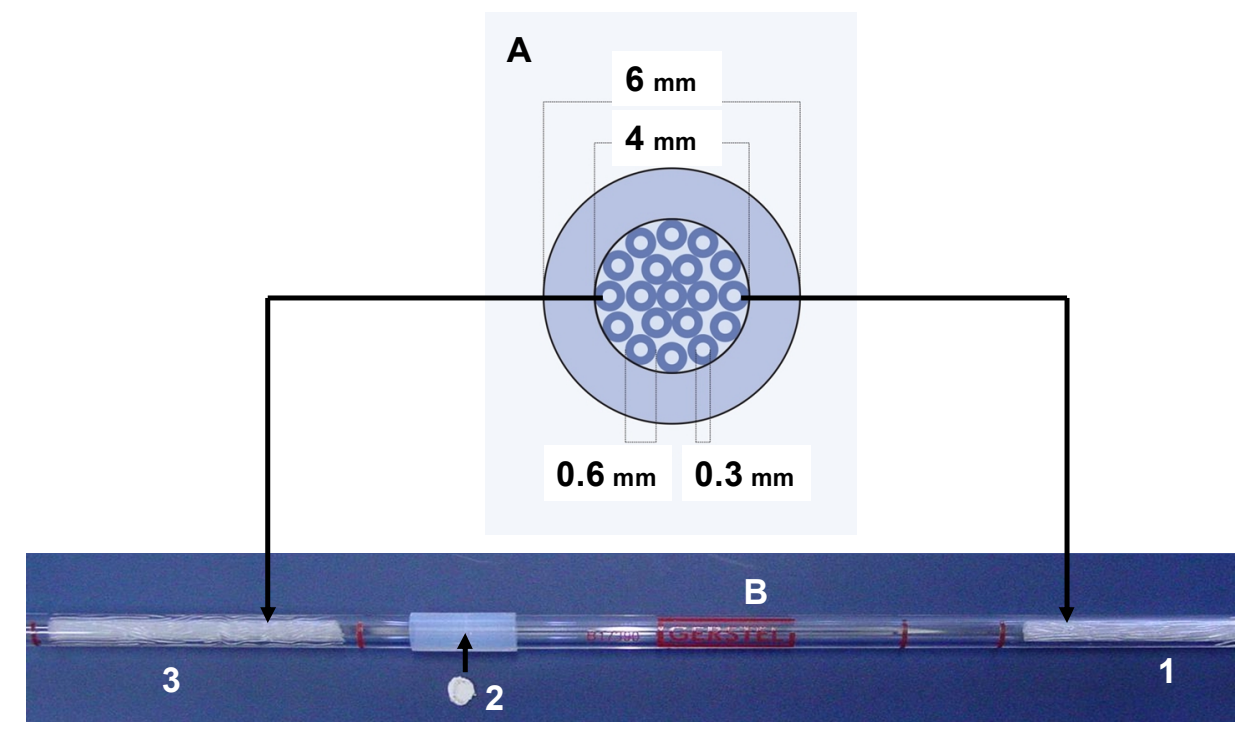

Figure 1. (A) Cross-section of a multichannel silicone rubber trap. ${ }^{1}$ Silicone elastomer (PDMS) tubes are arranged in parallel inside of a commercial glass desorption tube to give a PDMS sorptive volume of $600 \mu \mathrm{L}$. (B) A novel low pressure-drop miniature denuder (multi-channel PDMS trap $+{ }^{2}$ micro quartz fibre filter + multi-channel PDMS trap). The multi-channel PDMS traps and filter are tightly connected in series with a Teflon (PTFE) sleeve. ${ }^{1}$ Air borne vapour phase is collected on the first multi-channel PDMS trap and ${ }^{2}$ air borne particulate phase is collected on the micro quartz fibre filter. ${ }^{3}$ Back-up multi-channel PDMS trap to collect blow-off and potential break-through. Indoor air is sampled with a small and simple battery operated sampling pump at a low air flow sampling rate $\left(200 \mathrm{~mL} \mathrm{~min}{ }^{-}\right.$ $\left.{ }^{1}\right)$ and a short collection period (20 min). 


\subsubsection{Battery operated field pump}

Field gas sampling pumps were designed and built in-house, and included a model G-12/01 pump motor from Rietschle Thomas, Memmingen, Germany. The motor was driven by a constant voltage circuit which made the pump rate independent of battery voltage. Power was supplied by a rechargeable 7 voltampere (VA) lead battery (Electronics 123, Pretoria, South Africa).

\subsubsection{Indoor air sampling}

Indoor air samples were collected from traditional round thatch-roof huts in a rural village (S $23^{\circ} 02^{\prime} 02.3^{\prime \prime}$ E $30^{\circ} 51^{\prime} 33.5^{\prime \prime}$ ) in the Vhembe District, Limpopo Province, South Africa. The village is situated within an intermediate-risk malaria area where indoor DDT-spraying is performed annually [5]. A detailed description of the study area was reported in Van Dyk et al. [5]. Sampling was done in November 2007 during the early summer season. The province is a summer rainfall region. Indoor air samples were collected from a total of five huts over a period of five days. A single hut was sampled per day at 4 sampling intervals over a $24 \mathrm{~h}$ period. Four litre of indoor air was sampled at approximately $60 \mathrm{~cm}$ above ground level with a denuder (multi-channel PDMS trap + micro quartz fibre filter + multi-channel PDMS trap) at $200 \mathrm{~mL} \mathrm{~min}{ }^{-1}$ for $20 \mathrm{~min}$. Sampling took place prior to indoor DDT application (-1 h), immediately after application of DDT to the walls and ceilings of the rural dwellings ( 0 $\mathrm{h})$, after $4 \mathrm{~h}$, and after $24 \mathrm{~h}$ since DDT-spraying. 


\subsection{Indoor air analyses by GC-MS}

The analytes were desorbed form the first multi-channel PDMS traps (gaseous phase air borne contaminants) and the micro quartz fibre filters and backup multi-channel PDMS traps (particulate phase air borne contaminants) in a Gerstel thermal desorption system (TDS) installed on a Hewlett Packard (HP) GC 1530A coupled to a HP 5973 mass selective detector (MSD) (Chemetrix, Johannesburg, South Africa). The same instrumental conditions were used for analyses of gas phase air borne contaminants and for particulate phase air borne contaminants. The TDS transfer line temperature was $350^{\circ} \mathrm{C}$. During desorption the multi-channel PDMS traps were heated from $30^{\circ} \mathrm{C}(3 \mathrm{~min})$ at $30^{\circ} \mathrm{C} \min ^{-1}$ to $280{ }^{\circ} \mathrm{C}(15 \mathrm{~min})$ with a desorption flow rate of $100 \mathrm{~mL} \mathrm{~min}^{-1}$ at $65 \mathrm{kPa}$ (Helium, Ultra High Purity, Afrox, Johannesburg), enabling total transfer of analytes to the cold trap. The desorbed analytes were cryogenically focused on a Gerstel cooled injection system (CIS) at $50{ }^{\circ} \mathrm{C}$ using liquid nitrogen. The CIS liner was an open deactivated glass liner (Gerstel, Germany). After desorption, a splitless injection (purge on at 5 min, purge flow $80 \mathrm{~mL} \mathrm{~min}^{-1}$, solvent vent mode) was performed by heating the $\mathrm{CIS}$ from $-50{ }^{\circ} \mathrm{C}$ at $6{ }^{\circ} \mathrm{C} \mathrm{s}^{-1}$ to $250{ }^{\circ} \mathrm{C}$ maintained for $10 \mathrm{~min}$. GC separation was performed on a Zebron column, ZB1 30 m x $250 \mu \mathrm{m}$ ID x $0.25 \mu \mathrm{m}$ film thickness (Phenomenex, Separations, Randburg, South Africa), the velocity of the carrier gas (helium) was 33 $\mathrm{cm} \mathrm{s}^{-1}\left(0.7 \mathrm{~mL} \mathrm{~min}^{-1}\right)$ and the column head pressure was $65 \mathrm{kPa}$ in the constant pressure mode. The $\mathrm{GC}$ oven temperature programme was $150{ }^{\circ} \mathrm{C}(5 \mathrm{~min})$ at $10^{\circ} \mathrm{C}$ $\min ^{-1}$ to $210{ }^{\circ} \mathrm{C}$, at $5^{\circ} \mathrm{C} \min ^{-1}$ to $280{ }^{\circ} \mathrm{C}(1 \mathrm{~min})$. The $\mathrm{GC}$ run time was $26 \mathrm{~min}$. A post run was performed at $300^{\circ} \mathrm{C}(5 \mathrm{~min})$. The GC-MS transfer line was at $300^{\circ} \mathrm{C}$, 
the source $(\mathrm{El}+)$ temperature $230^{\circ} \mathrm{C}$, the MS quadrupole temperature $150^{\circ} \mathrm{C}$, the ionisation energy $70 \mathrm{eV}$ and the electron multiplier (EM) $1700 \mathrm{~V}$.

A chromatogram was recorded in full scan mode $(45-450 \mathrm{~m} / \mathrm{z})$ to identify the target analytes and to determine their respective retention times. Thereafter, all analyses and quantification were performed in the more sensitive selected ion monitoring (SIM) mode. For DDE the selected ions were $246 \mathrm{~m} / \mathrm{z}, 248 \mathrm{~m} / \mathrm{z}, 318 \mathrm{~m} / \mathrm{z}$ (100 ms dwell time), whilst for DDD, DDT as well as ${ }^{13} \mathrm{C}_{12}-p, p^{\prime}$-DDT (IS) the selected ions were $165 \mathrm{~m} / \mathrm{z}, 235 \mathrm{~m} / \mathrm{z}, 237 \mathrm{~m} / \mathrm{z}, 247 \mathrm{~m} / \mathrm{z}, 249 \mathrm{~m} / \mathrm{z}, 330 \mathrm{~m} / \mathrm{z}(50 \mathrm{~ms}$ dwell time). Blanks (PDMS traps and filters) were routinely analysed. Separate GCMS runs were performed, under the same instrumental conditions, for air borne vapour phase DDT (first multi-channel PDMS trap) and air borne particulate phase DDT (filter and back-up multi-channel PDMS trap).

\subsubsection{Quantification}

GC-MS calibration was performed by addition of $1 \mathrm{uL}$ of each of the calibration

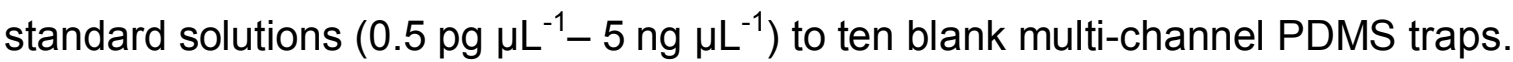
One microlitre of the isotope-labeled ring substituted ${ }^{13} \mathrm{C}_{12}-p, p^{\prime}-\mathrm{DDT}$ working solution was added as an internal standard $\left(1 \mathrm{ng} \mathrm{hL}^{-1}\right)$ to each of the ten calibration PDMS traps, and as well as to the indoor air enriched PDMS traps and filters. The internal standard (IS) method of quantification was done. Calibration curves $(n=10)$ were constructed by plotting response factors (peak area $a_{\text {Analyte }} /$ peak area $a_{\text {Internal standard }}$ ) for each of the compounds. The results of the linear regression analysis are depicted in Table 1. 
Table 1

Linear regression analysis for $p, p^{\prime}-\mathrm{DDT}, o, p^{\prime}-\mathrm{DDT}, p, p^{\prime}-\mathrm{DDD}, o, p^{\prime}-\mathrm{DDD}, p, p^{\prime}-\mathrm{DDE}$ and $o, p^{\prime}-\mathrm{DDE}$

\begin{tabular}{|c|c|c|c|c|c|}
\hline Compound & $\begin{array}{l}\text { Quantification lon } \\
\qquad \mathrm{m} / \mathrm{z}\end{array}$ & ${ }^{1}$ Regression Equation & $\begin{array}{l}R^{2} \\
(n=10)\end{array}$ & $\begin{array}{l}{ }^{2} \text { LOD } \mathrm{ng} \mathrm{m}^{-3} \\
\left(\mathrm{pg} \mathrm{L}^{-1}\right)\end{array}$ & $\begin{array}{l}{ }^{3} \mathrm{LOQ} \mathrm{ng} \mathrm{m}^{-3} \\
\left(\mathrm{pg} \mathrm{L}^{-1}\right)\end{array}$ \\
\hline 2, 4'-DDE & 246 & $y=4.8792 x+0.0856$ & 0.997 & 0.0683 & 0.2277 \\
\hline 4,4'-DDE & 246 & $y=2.1537 x+0.053$ & 0.998 & 0.1196 & 0.3987 \\
\hline 2,4'-DDD & 235 & $y=3.1319 x+0.1555$ & 0.999 & 0.1337 & 0.4456 \\
\hline 4,4'-DDD & 235 & $y=2.5899 x+0.016$ & 0.998 & 0.2669 & 0.8897 \\
\hline 2,4'-DDT & 235 & $y=2.0905 x+0.0383$ & 0.999 & 0.2967 & 0.9891 \\
\hline 4,4'-DDT & 235 & $y=0.8885 x+0.0006$ & 0.998 & 0.3515 & 1.1715 \\
\hline
\end{tabular}

Compounds listed in order of elution (apolar separation). Quantification ion for internal standard $\left({ }^{13} \mathrm{C}_{12}-p, p^{\prime}-\mathrm{DDT}\right)$ is $247 \mathrm{~m} / \mathrm{z} .{ }^{1} y=$ peak area of compound/peak area of internal standard $\left({ }^{13} \mathrm{C}_{12}-p, p^{\prime}\right.$-DDT); $x=$ concentration of the compound $\mathrm{ng} 4 \mathrm{~L}^{-1}$. ${ }^{2}$ Limit of detection (LOD) calculated as the concentration that gives a signal-to-noise ratio of 3 . ${ }^{3}$ Limit of quantification (LOQ) calculated as the concentration that gives a signal-to-noise ratio of 10 . 


\section{Results and discussion}

\subsection{Evaluation of p,p'-DDT degradation during thermal desorption and CIS injection}

It is well known that DDT can degrade to DDD and DDE on a hot inlet surface. DDT degradation is not due to DDT being thermally labile, but due to active sites in the GC inlet. Activity in the injection port liner of a GC is increased at a high inlet temperature. The boiling point of DDT is $260{ }^{\circ} \mathrm{C}$ [25] and a typical GC inlet temperature for DDT is $250^{\circ} \mathrm{C}$. Drawing conclusions as to whether DDD and DDE are due to environmental degradation rather than degradation in a GC inlet are therefore problematic. In general, an accepted break-down limit of $p, p^{\prime}-\mathrm{DDT}$ degradation in the inlet is $15 \%$ [26]. $p, p^{\prime}$-DDT degradation in the inlet often exceeds $15 \%$ and can be as high as $65 \%$ [27]. The Gerstel CIS is a programmed temperature vaporising injector (PTV) resulting in injection at a lower temperature. CIS inlet liner dimensions ( $2 \mathrm{~mm} I D, 70 \mathrm{~mm}$ long) are smaller compared to conventional GC inlet liners (4 mm ID, $78 \mathrm{~mm}$ long). Therefore, the potentially active glass surface area of a CIS liner is relatively small compared to a regular inlet liner.

To evaluate the potential for degradation of $p, p$-DDT during thermal desorption and CIS injection, multi-channel PDMS traps were spiked with $1 \mathrm{ng} \mathrm{LL}^{-1}$ of $p, p^{\prime}-\mathrm{DDT}$ degradation solution (section 2.1). The spiked multi-channel PDMS traps were desorbed using various TDS and CIS heating rates (Table 2). The CIS was heated from $-50{ }^{\circ} \mathrm{C}$ to $250{ }^{\circ} \mathrm{C}$ and the TDS from $30{ }^{\circ} \mathrm{C}$ to $280{ }^{\circ} \mathrm{C}$ for all experiments. Degradation of $p, p^{\prime}-$ DDT $(22 \%)$ was the greatest at a slow TDS heat rate $\left(10^{\circ} \mathrm{C} \mathrm{min}\right.$ $\left.{ }^{1}\right)$ and a slow $\mathrm{CIS}$ heat rate $\left(3{ }^{\circ} \mathrm{C} \mathrm{s}^{-1}\right)$ (Table 2). Analyte degradation (8\%-11\%) decreased at faster TDS and CIS heating rates (Table 2). Slower heating rates 
result in prolonged analyte contact time and an associated increase in degradation. Inlet liners were replaced regularly with new deactivated liners to control DDT degradation.

TDS-CIS injection was then compared to isothermal injection at $250{ }^{\circ} \mathrm{C}$ with the same CIS inlet, only now the inlet was in conventional GC inlet mode (septumless samplehead) instead of CIS-PTV mode. Conventional isothermal injection of $1 \mu \mathrm{L}$ of the inlet degradation solution at $250{ }^{\circ} \mathrm{C}$ produced $p, p^{\prime}$-DDT degradation of $36 \%$ (Table 2). This confirmed that TDS and cryogenic focusing of analytes prior to injection, followed by injection with ramped heating of the inlet to $250^{\circ} \mathrm{C}$, is a milder sample introduction technique, causing less $p, p^{\prime}$-DDT degradation, when compared to conventional isothermal injection at $250^{\circ} \mathrm{C}$.

Table 2

Comparison of the effect of TDS and CIS heating rates and of conventional injection on $\%$ degradation of DDT

Thermal desorption/injection

TDS heat rate/CIS heat rate

DDT degradation (\%)

$\begin{array}{lc}10^{\circ} \mathrm{C} \mathrm{min}^{-1} / 3{ }^{\circ} \mathrm{C} \mathrm{s}^{-1} & 22 \\ 30{ }^{\circ} \mathrm{C} \mathrm{min}^{-1} / 3{ }^{\circ} \mathrm{C} \mathrm{s}^{-1} & 12 \\ 60{ }^{\circ} \mathrm{C} \mathrm{min}^{-1} / 3{ }^{\circ} \mathrm{C} \mathrm{s}^{-1} & 14 \\ 30{ }^{\circ} \mathrm{C} \mathrm{min}^{-1} / 6{ }^{\circ} \mathrm{C} \mathrm{s}^{-1} & 8 \\ 60{ }^{\circ} \mathrm{C} \mathrm{min}^{-1} / 6{ }^{\circ} \mathrm{C} \mathrm{s}^{-1} & 11 \\ 30{ }^{\circ} \mathrm{C} \mathrm{min}^{-1} / 12{ }^{\circ} \mathrm{C} \mathrm{s}^{-1} & 9 \\ 60{ }^{\circ} \mathrm{C} \mathrm{min}^{-1} / 12{ }^{\circ} \mathrm{C} \mathrm{s}^{-1} & 10\end{array}$




\subsection{Vapour phase and particulate phase DDT in indoor air}

The isotope-labeled internal standard (ring substituted ${ }^{13} \mathrm{C}_{12}-p, p^{\prime}$-DDT) method of calibration and linear regression analysis (Table 1) were used to quantify $p, p$ 'DDT, $o, p^{\prime}-\mathrm{DDT}, p, p^{\prime}-\mathrm{DDD}, o, p^{\prime}-\mathrm{DDD}, p, p^{\prime}-\mathrm{DDE}$ and $o, p^{\prime}-\mathrm{DDE}$ in contaminated indoor air. Limits of detection were $0.07-0.35 \mathrm{ng} \mathrm{m}^{-3}$ for $p, p^{\prime}$-DDT, $o, p^{\prime}$-DDT, $p, p^{\prime}$-DDD, $o, p^{\prime}-$ DDD, $p, p^{\prime}$-DDE and $o, p^{\prime}$-DDE (Table 1). Should lower LODs be required negative chemical ionisation, instead of $\mathrm{El}+$, can be used. Figure 2 depicts a chromatogram (SIM mode) of a low calibration standard $0.5 \mathrm{pg} \mathrm{\mu L}^{-1}-2.4 \mathrm{pg} \mathrm{hL}^{-1}$, and overlays of chromatograms of indoor air prior to DDT IRS and after DDT IRS.

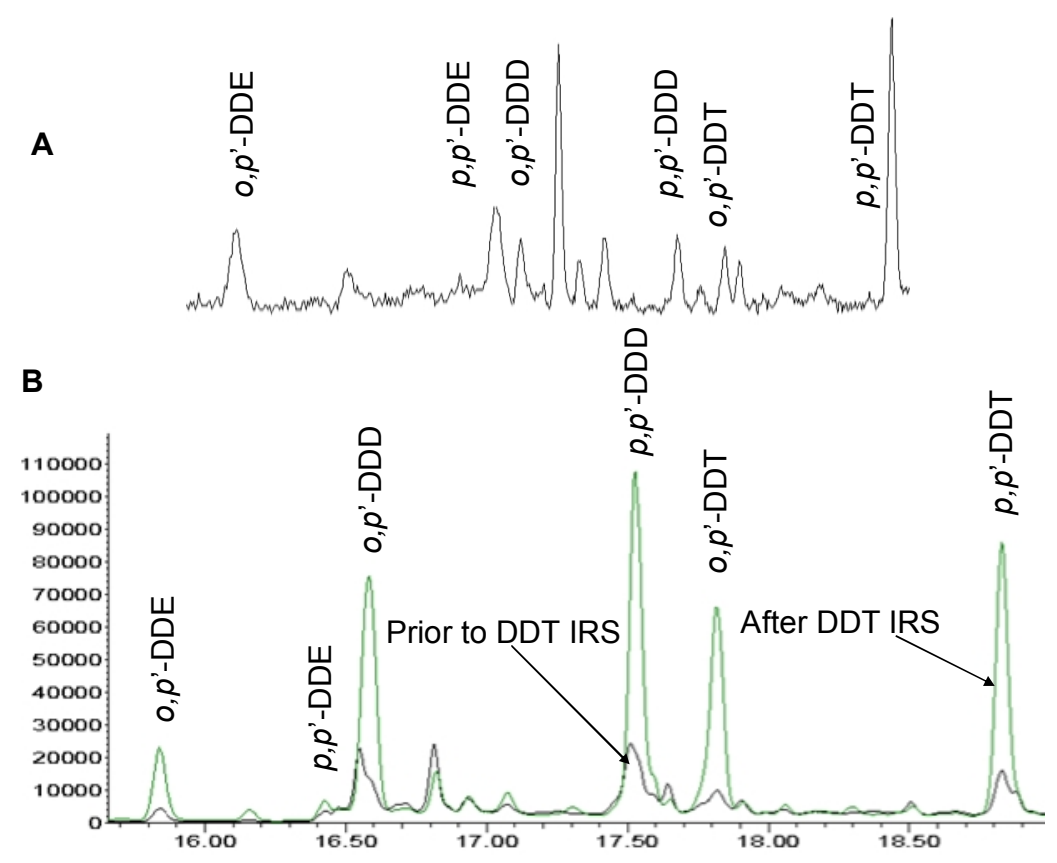

Figure 2. (A) SIM chromatogram of the lowest calibration standard $0.5 \mathrm{pg} \mathrm{pL}^{-1}-$ $2.4 \mathrm{pg} \mathrm{hL}^{-1}$. (B) Overlay of SIM chromatograms of $4 \mathrm{~L}$ of indoor air: prior to DDT IRS and after DDT IRS.

Vapour phase and particle bound $p, p^{\prime}$-DDT, o, $p^{\prime}$-DDT, $p, p^{\prime}$-DDD, o, $p^{\prime}$-DDD, $p, p^{\prime}-$ DDE and $o, p^{\prime}-\mathrm{DDE}$ were concentrated from $4 \mathrm{~L}$ indoor air using a simple, off-line 
battery operated, small field sampler consisting of a novel serially fitted low pressuredrop denuder (multi-channel PDMS trap + micro quartz fibre filter + multi-channel PDMS trap) (Section 2.2, Fig. 1). At the low flow rate $\left(200 \mathrm{~mL} \mathrm{~min}^{-1}\right)$ employed, the pump motor drew approximately 10 milliampere $(\mathrm{mA})$, which allows for a theoretical pump run time of approximately 700 hours from a battery in good condition, before requiring a recharge. However, batteries were recharged daily. The hydrophobic silicone rubber absorption medium is not sensitive to moist air. A denuder allows simultaneous collection of molecules and transmission of aerosol particles through the silicone rubber tubes based on the large difference in radial diffusion speeds in the axial laminar flow environment [24]. Simply put, molecules diffuse fast enough to reach the absorption medium whereas (heavy) particles are blown straight through because of their slow radial movement. Airborne vapour phase contaminants are collected on the first multi-channel PDMS trap and airborne particulate phase contaminants are collected downstream on a serially fitted quartz micro-fibre filter (Fig. 1). A second multi-channel PDMS trap is useful as a back-up trap to collect blow-off and potential break-through (Fig. 1). Sampling was performed at a low air

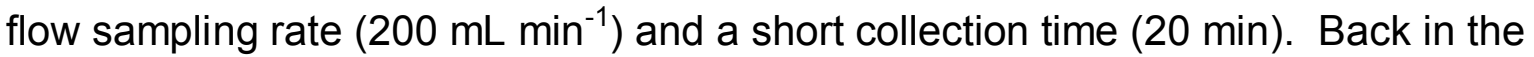
laboratory, solvent extraction of the concentration materials was not required. Instead, thermal desorption allowed solvent-free transfer of the entire collected sample mass to the cryo-cooled (liquid nitrogen) inlet of a GC-MS. To test the desorption efficiency of analytes from multi-channel PDMS traps and filters during TDS, previously analysed multi-channel PDMS traps and filters were immediately redesorbed in consecutive runs. Quantitative removal of analytes from multichannel PDMS traps and filters were confirmed, since analytes were not detected during these second runs. 
The many benefits of TDS-CIS are depicted in Table 3. A disadvantage is that thermal desorption consumes the full sample, preventing repeat injections often performed for liquid extracts (Table 3). Storage of an analysed sample is also not possible. The rather substantial cost of a TDS-CIS system may be considered against the cost saving gained by a sample preparation-free and solvent-free system. Instead of liquid nitrogen, a packed liner may be used to focus DDT at room temperature. The advantage of two separate airborne contaminant phases can still be attained by laboratories not equipped with a TDS. In such cases PDMS and filter denuder materials may be solvent extracted.

Table 3

Advantages and disadvantages of thermal desorption/injection (TDS-CIS)

Advantage Disadvantage

Sample preparation not required

Total sample is consumed

-Minimises analyte loss

-Minimises introduction of artefacts

Cost/Availability

-Cost saving -TDS-CIS system

Solvent free ("green") -liquid nitrogen

-No solvent waste disposal

-No solvent associated artefacts

-No exposure of staff to solvent

-Cost saving

Sample not diluted

-Enhanced detection limit

Lower injection temperature minimises DDT conversion 
Figure 3 illustrates the mean contribution $\left(\mu \mathrm{g} \mathrm{m}^{-3}\right)$ across five huts of vapour phase and particulate phase $p, p^{\prime}-\mathrm{DDT}, o, p^{\prime}-\mathrm{DDT}, p, p^{\prime}-\mathrm{DDD}, o, p^{\prime}-\mathrm{DDD}, p, p^{\prime}-\mathrm{DDE}$ and $o, p^{\prime}-\mathrm{DDE}$ in indoor air over a $24 \mathrm{~h}$ period. Airborne DDT was present in both vapour phase and in particulate phase in indoor air prior to DDT-spraying (Table 4). Directly after indoor residual spraying (IRS) vapour phase and particulate phase mean $(n=5)$ $\Sigma$ DDT increased. A recommendation is that inhabitants should remain outside their dwellings for at least an hour after technical DDT application [28]. However, $24 \mathrm{~h}$ after IRS vapour phase mean $\Sigma$ DDT was at a maximum (possibly due to DDT spray drift from a larger number of huts sprayed in the village within a $24 \mathrm{~h}$ period). Particulate phase mean $\Sigma$ DDT showed a minor decrease over a $24 \mathrm{~h}$ period after IRS (under undisturbed dust conditions). Mean $(n=5) \Sigma$ DDT was largely present as vapour phase in indoor air (Table 4). Compared to DDT and DDD, vapour phase fractions of $p, p^{\prime}-\mathrm{DDE}$ were lower. $p, p^{\prime}-\mathrm{DDE}$, a potent endocrine disrupting chemical [29], is reported to show highest bioaccumulation in human fatty tissue when compared to DDD and DDT $[29,30]$. It is assumed that phase distribution of the compounds depend on the particulate mass concentration and the ambient temperature: the higher the temperature the more the equilibrium shifts to the gas phase [8]. 


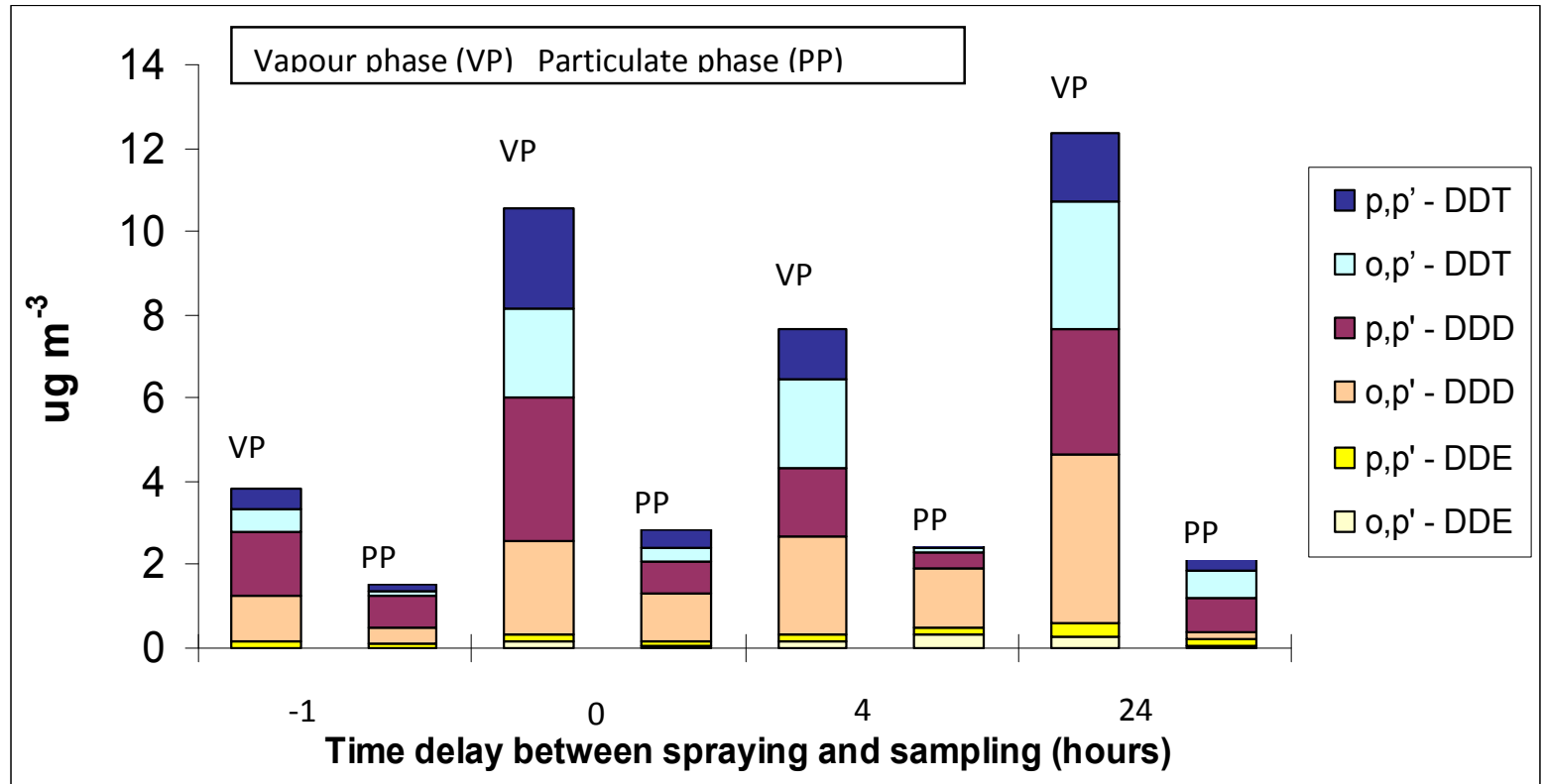

Figure 3. Concentrations of $p, p^{\prime}-\mathrm{DDT}, o, p^{\prime}-\mathrm{DDT}, p, p^{\prime}-\mathrm{DDD}, o, p^{\prime}-\mathrm{DDD}, p, p^{\prime}-\mathrm{DDE}$ and $o, p^{\prime}-\mathrm{DDE}\left(\mu \mathrm{g} \mathrm{m}{ }^{-3}\right)$ in vapour (VP) and particulate phases (PP) in indoor air averaged for five huts. Sampling intervals: $-1 \mathrm{~h}$ prior to DDT-spraying; $0 \mathrm{~h}$ directly after DDTspraying; $4 \mathrm{~h}$ after DDT-spraying; $24 \mathrm{~h}$ after DDT-spraying. $4 \mathrm{~L}$ indoor air borne vapour phase was collected on a multi-channel PDMS trap and air borne particulate phase was collected down-stream on a quartz micro-fibre filter and a second multichannel PDMS trap. Levels of DDD are higher than DDT across sampling intervals. $4 \mathrm{~h}$ after IRS levels of $o, p^{\prime}$-DDT are higher than $p, p^{\prime}$-DDT. Vapour phase mean $\Sigma$ DDT is highest $24 \mathrm{~h}$ after IRS, possibly due to DDT spray drift from a larger number of huts sprayed within a $24 \mathrm{~h}$ period. Particulate phase $\Sigma$ DDT showed a minor decrease over a $24 \mathrm{~h}$ period after IRS. For details see text 3.2. 
Table 4

DDT, DDD, DDE $\left(\mu \mathrm{g} \mathrm{m}^{-3}\right)$ in indoor air and fraction of the concentration in vapour phase $(\%)$ of five huts sampled at intervals prior to IRS, directly after IRS, $4 \mathrm{~h}$ and $24 \mathrm{~h}$ after IRS

\begin{tabular}{|c|c|c|c|c|c|c|c|c|}
\hline \multirow[t]{3}{*}{ Compound } & \multicolumn{3}{|c|}{ Vapour phase (VP) } & \multicolumn{3}{|c|}{ Particulate phase (PP) } & \multirow{3}{*}{$\begin{array}{c}\text { VP+PP } \\
\text { Total } \\
\text { airborne }\end{array}$} & \multirow{3}{*}{$\begin{array}{c}\text { Vapour } \\
\text { phase } \\
\text { fraction \% }\end{array}$} \\
\hline & \multirow{2}{*}{$\begin{array}{c}\text { Mean } \\
(\mathrm{n}=5)\end{array}$} & \multicolumn{2}{|c|}{ Range } & \multirow{2}{*}{$\begin{array}{c}\text { Mean } \\
(n=5)\end{array}$} & \multicolumn{2}{|c|}{ Range } & & \\
\hline & & Min & Max & & Min & Max & & \\
\hline \multicolumn{9}{|l|}{-1 h prior to IRS } \\
\hline$o, p^{\prime}-\mathrm{DDE}$ & 0.02 & 0.01 & 0.03 & 0.003 & $<\mathrm{LOD}^{1}$ & 0.003 & 0.023 & 89.1 \\
\hline$p, p^{\prime}$ - DDE & 0.15 & 0.03 & 0.26 & 0.09 & $<$ LOD & 0.09 & 0.24 & 61.4 \\
\hline$o, p^{\prime}-$ DDD & 1.12 & 0.10 & 1.92 & 0.4 & 0.15 & 0.61 & 1.51 & 73.8 \\
\hline$p, p^{\prime}-\mathrm{DDD}$ & 1.48 & 0.27 & 3.00 & 0.77 & 0.54 & 1.33 & 2.25 & 65.7 \\
\hline$o, p^{\prime}-$ DDT & 0.58 & 0.36 & 0.80 & 0.08 & 0.12 & 0.13 & 0.66 & 87.5 \\
\hline$p, p^{\prime}$ - DDT & 0.47 & 0.18 & 0.63 & 0.17 & 0.06 & 0.37 & 0.64 & 73.4 \\
\hline $\mathrm{t}-\mathrm{DDE} \mathrm{E}^{2}$ & 0.17 & & & 0.09 & & & 0.26 & \\
\hline $\mathrm{t}-\mathrm{DDD}$ & 2.60 & & & 1.17 & & & 3.77 & \\
\hline t-DDT & 1.05 & & & 0.25 & & & 1.30 & \\
\hline$\Sigma$-DDT & 3.82 & & & 1.52 & & & 5.33 & \\
\hline
\end{tabular}

$\underline{0 \mathrm{~h} \text { after IRS }}$

\begin{tabular}{|c|c|c|c|c|c|c|c|}
\hline$o, p^{\prime}$ - DDE & 0.14 & 0.09 & 0.2 & 0.04 & $<L O D$ & 0.11 & 0.18 \\
\hline$p, p^{\prime}-\mathrm{DDE}$ & 0.18 & 0.13 & 0.26 & 0.14 & $<$ LOD & 0.27 & 0.32 \\
\hline$o, p^{\prime}-\mathrm{DDD}$ & 2.23 & 1.69 & 3.09 & 1.13 & 0.31 & 2.84 & 3.36 \\
\hline$p, p^{\prime}$ - DDD & 3.45 & 1.25 & 8.21 & 0.79 & 0.57 & 1.25 & 4.23 \\
\hline$o, p^{\prime}-\mathrm{DDT}$ & 2.13 & 1.11 & 4.28 & 0.28 & 0.01 & 0.84 & 2.41 \\
\hline$p, p^{\prime}-\mathrm{DDT}$ & 2.42 & 0.74 & 5.41 & 0.49 & 0.14 & 1.18 & 2.91 \\
\hline t-DDE & 0.33 & & & 0.18 & & & 0.51 \\
\hline t-DDD & 5.68 & & & 1.91 & & & 7.59 \\
\hline t-DDT & 4.55 & & & 0.77 & & & 5.33 \\
\hline$\Sigma$-DDT & 10.56 & & & 2.87 & & & 13.43 \\
\hline
\end{tabular}


$\underline{4 h}$ after IRS

\begin{tabular}{|c|c|c|c|c|c|c|c|}
\hline$o, p^{\prime}$ - DDE & 0.17 & 0.03 & 0.31 & 0.33 & 0.11 & 0.56 & 0.5 \\
\hline$p, p^{\prime}$ - DDE & 0.19 & 0.14 & 0.28 & 0.14 & 0.02 & 0.36 & 0.33 \\
\hline$o, p^{\prime}$ - DDD & 2.34 & 0.59 & 3.73 & 1.45 & 0.23 & 3.75 & 3.79 \\
\hline$p, p^{\prime}$ - DDD & 1.63 & 0.63 & 2.53 & 0.4 & 0.02 & 0.72 & 2.03 \\
\hline$o, p^{\prime}$ - DDT & 2.13 & 0.65 & 3.93 & 0.07 & 0.01 & 0.19 & 2.2 \\
\hline$p, p^{\prime}$ - DDT & 1.23 & 0.41 & 3.11 & 0.36 & 0.19 & 0.85 & 1.59 \\
\hline t-DDE & 0.35 & & & 0.47 & & & 0.83 \\
\hline t-DDD & 3.97 & & & 1.85 & & & 5.82 \\
\hline t-DDT & 3.36 & & & 0.44 & & & 3.80 \\
\hline$\Sigma$-DDT & 7.68 & & & 2.76 & & & 10.44 \\
\hline
\end{tabular}

\section{$\underline{24 \mathrm{~h} \text { after IRS }}$}

\begin{tabular}{|c|c|c|c|c|c|c|c|c|}
\hline$o, p^{\prime}-\mathrm{DDE}$ & 0.27 & 0.02 & 0.70 & 0.06 & 0.06 & 0.06 & 0.33 & 81.7 \\
\hline$p, p^{\prime}$ - DDE & 0.35 & 0.06 & 0.84 & 0.14 & 0.001 & 0.42 & 0.49 & 71.3 \\
\hline$o, p^{\prime}-\mathrm{DDD}$ & 4.01 & 0.45 & 9.72 & 0.18 & 0.15 & 0.21 & 4.19 & 95.7 \\
\hline$p, p^{\prime}-\mathrm{DDD}$ & 3.03 & 0.86 & 6.36 & 0.83 & 0.38 & 1.68 & 3.86 & 78.5 \\
\hline$o, p^{\prime}-\mathrm{DDT}$ & 3.07 & 0.59 & 6.78 & 0.63 & 0.004 & 1.86 & 3.70 & 83.1 \\
\hline$p, p^{\prime}$ - DDT & 1.64 & 1.30 & 2.01 & 0.46 & 0.27 & 0.63 & 2.10 & 78.1 \\
\hline t-DDE & 0.62 & & & 0.20 & & & 0.82 & \\
\hline t-DDD & 7.04 & & & 1.01 & & & 8.05 & \\
\hline t-DDT & 4.71 & & & 1.09 & & & 5.80 & \\
\hline$\Sigma$-DDT & 12.37 & & & 2.30 & & & 14.67 & \\
\hline
\end{tabular}

'Limit of detection ${ }^{2} \mathrm{t}$-DDT was calculated as the sum of $p, p$ '-DDT and $o, p$ '-DDT; t-DDD was calculated as the sum of $p, p^{\prime}-\mathrm{DDD}$ and $o, p^{\prime}-\mathrm{DDD}$; and t-DDE was calculated as the sum of $p, p^{\prime}-\mathrm{DDE}$ and $o, p^{\prime}-\mathrm{DDE}$ 


\subsubsection{Ratios of o, $p^{\prime}-D D T$ relative to $p, p^{\prime}-D D T$}

Technical grade DDT ( $75 \%$ wettable powder) used for IRS in South Arica contains $72-75 \%$ of $p, p^{\prime}-\mathrm{DDT}$, the active ingredient, and $\sim 22 \%$ of $o, p^{\prime}$-DDT $[28,31]$. Prior to, and directly after DDT-spraying, vapour phase $p, p^{\prime}-\mathrm{DDT}$ and vapour phase $o, p^{\prime}$-DDT were present in approximately equal ratios, while particulate phase $p, p^{\prime}$ DDT was higher than particulate phase $o, p^{\prime}$-DDT (Fig. 3). However, $4 \mathrm{~h}$ to $24 \mathrm{~h}$ after DDT-spraying vapour phase $p, p^{\prime}$-DDT ( $\left.36 \%\right)$ was considerably lower than vapour phase $o, p^{\prime}$-DDT, whilst after $4 \mathrm{~h}$ particle phase $p, p^{\prime}$-DDT was considerably greater than particle phase $o, p^{\prime}-\mathrm{DDT}$. Twenty four hours after IRS particle phase $p, p^{\prime}$-DDT was less than particle phase $o, p^{\prime}$-DDT. Bouwman et al. [28] demonstrated that relative to $p, p^{\prime}-\mathrm{DDT}, o, p^{\prime}$-DDT constituted $\sim 75 \%$, of the indoor air of huts after IRS. The authors' results support our measurements of higher levels of $o, p^{\prime}$-DDT relative to $p, p^{\prime}$-DDT in indoor air, as Bouwman et al.'s [28] sampling was conducted concurrently with our sampling. According to Bouwman et al. [28] two types of IRS products were used during the 2007 season, one product containing significantly higher levels of $o, p^{\prime}$-DDT compared to $p, p^{\prime}$-DDT. To our knowledge $p, p^{\prime}$-DDT does not change to $o, p^{\prime}-\mathrm{DDT}$ under environmental conditions. This unusual $o, p^{\prime}-\mathrm{DDT} / p, p^{\prime}-$ DDT ratio is not typical of technical DDT, instead it is somewhat similar to the ratio of dicofol-associated DDT [32].

Because $p, p^{\prime}$-DDT degrades to $p, p^{\prime}-\mathrm{DDE}$ only under aerobic conditions and to $p, p^{\prime}$-DDD only under anaerobic conditions [33-35], it can be safely concluded that the DDT products used prior to and during IRS 2007 contained very little $p, p^{\prime}-\mathrm{DDT}$ relative to $o, p^{\prime}$-DDT. Since it is only $p, p^{\prime}$-DDT that is effective against the malaria 
carrying mosquito this diminished insecticidal potency represented by the low levels of $p, p^{\prime}$-DDT present in DDT products is a major cause for concern. Of interest is that an investigation of POPs in the Southern Hemisphere resulting from atmospheric transport showed that soils from the Eastern coast of Antarctica also contained higher proportions of $o, p^{\prime}$-DDT relative to $p, p^{\prime}$-DDT [36].

\subsubsection{Ratios of $D D D$ and $D D E$ relative to $D D T$}

Total airborne DDT, DDD and DDE was calculated as the sum of vapour and particulate phases (VP+PP) (Table 4). The level of total airborne DDD $\left(3.77 \mu \mathrm{g} \mathrm{m}^{-3}\right)$ was higher than total airborne DDT $\left(1.3 \mu \mathrm{g} \mathrm{m}^{-3}\right)$ prior to DDT-spraying, and as well as over a $24 \mathrm{~h}$ period after DDT-spraying (Table 4, Fig.3). Technical DDT contains, as by-products, less than $1 \% o, p^{\prime}$-DDD, $p, p^{\prime}$-DDD, $o, p^{\prime}$-DDE and $p, p^{\prime}$-DDE [37]. $p, p^{\prime}-$ DDT in the environment degrades to $p, p^{\prime}-\mathrm{DDD}$ under anaerobic conditions and to $p, p$ '-DDE under aerobic conditions [33-35]. Therefore, DDE formation is favoured in well aerated soil [12]. Because emissions from residues present in soil is a source of pollutants in air [12], DDE rather than DDD is expected to be present in the indoor air of the huts. Thus, the surprisingly elevated level of total (gas+particulate phases) airborne DDD prior to IRS is not the result of weathered DDT, since under the prevailing conditions DDE formation is favoured over DDD. Directly after DDTspraying total airborne DDD of $7.59 \mu \mathrm{g} \mathrm{m}^{-3}$ was double the amount of total airborne DDD just prior to DDT-spraying (Table 4). This implies that DDT products used during IRS 2006 and IRS 2007 seasons contained a significant amount of DDD. Prior to DDT-spraying total airborne DDD constituted $71 \%$ of total airborne $\Sigma$ DDT while after DDT-spraying total airborne DDD constituted $\sim 57 \%$ of total airborne $\Sigma$ 
DDT. Alarmingly, it appears that the IRS DDT product used at the time of our study contained significantly less than the required $\sim 73 \% p, p^{\prime}-\mathrm{DDT}$, and an unusually high level of DDD.

Given that technical grade $p, p^{\prime}-\mathrm{DDT}$ should contain very little $p, p^{\prime}-\mathrm{DDD}$ and $p, p^{\prime}-\mathrm{DDE}$ the presence of $p, p^{\prime}-\mathrm{DDD}$ and $p, p^{\prime}-\mathrm{DDE}$ in the environment is usually an indication of DDT degradation. $p, p^{\prime}-\mathrm{DDE} / p, p^{\prime}-\mathrm{DDT}$ and $p, p^{\prime}-\mathrm{DDD} / p, p^{\prime}-\mathrm{DDT}$ ratios have been used to determine recent or historical p,p'-DDT usage [12]. As discussed previously, anaerobic environmental conditions favour $p, p^{\prime}$-DDD formation over $p, p^{\prime}-$ DDE [33-35]. Degraded residues in well aerated soils therefore generally contain less $p, p^{\prime}-\mathrm{DDD}$ than $p, p^{\prime}-\mathrm{DDE}$ [12]. Batterman et al. [12] reported a $p, p^{\prime}-\mathrm{DDE} / p, p^{\prime}-$ DDT ratio of 0.29 in ambient air in Durban, South Africa. The p,p'-DDD/p,p'-DDT ratio in ambient air in Durban should then be lower than the reported $p, p^{\prime}-\mathrm{DDE} / p, p^{\prime}-$ DDT ratio of 0.29 . However, Batterman et al. [12] described airborne levels of $p, p^{\prime}-$ DDD almost equal to $p, p^{\prime}-\mathrm{DDT}$, and in some air samples $p, p^{\prime}$-DDD exceeded $p, p^{\prime}-$ DDT in ambient air in Durban, South Africa. The authors suggested that this unusual $p, p^{\prime}-\mathrm{DDD} / p, p^{\prime}-\mathrm{DDT}$ mean ratio of 0.60 for ambient air in Durban may be due to current use of DDT formulations that differ from formulations used in the past [12], which would explain these excessive $p, p^{\prime}$-DDD levels. Historically, $p, p^{\prime}$-DDD was produced as an insecticide, although its efficacy was lower compared to $p, p^{\prime}$-DDT [12], while $o, p^{\prime}-\mathrm{DDD}$ has been used medically to treat cancer [38, 39]. The presence of unusual elevated levels of airborne $p, p^{\prime}-\mathrm{DDD}$ in South Africa are indeed substantiated by our measured ratios of indoor airborne $p, p^{\prime}-\mathrm{DDD} / p, p^{\prime}-\mathrm{DDT}$ which were 3.52 prior to DDT-spraying, and 1.52 after IRS in Limpopo Province, South Africa. $p, p^{\prime}-\mathrm{DDD} / p, p^{\prime}-\mathrm{DDT}$ ratios significantly below 1 are anticipated directly after DDT-spraying. However, even directly after spraying the level of indoor airborne 
DDD in traditional huts in the Limpopo Province still exceeds that of airborne $p, p^{\prime}$ DDT, suggesting that technical DDT contained levels of DDD exceeding the required product composition. It was confirmed that the DDT IRS 2006 product contained more DDD than DDT (personal communication, 2008). Unfortunately, we could not obtain a sample of the commercial DDT product.

A high $p, p^{\prime}-\mathrm{DDE} / p, p^{\prime}-\mathrm{DDT}$ ratio generally indicates ageing of DDT [12]. As expected, low indoor airborne $p, p^{\prime}-\mathrm{DDE} / p, p^{\prime}-\mathrm{DDT}$ ratios for Vhembe in Limpopo Province, South Africa were measured. $p, p^{\prime}-\mathrm{DDE} / p, p^{\prime}-\mathrm{DDT}$ ratios prior to DDTspraying were 0.37 and after DDT-spraying it was 0.18 .

\subsubsection{Indoor air chemical profile}

IRS takes place annually [5]. However, increases in cases of malaria outbreaks following IRS have been reported which then necessitates a second round of IRS (personal communication, 19 August 2009). Ratios of indoor airborne $p, p$ '$\mathrm{DDD} / p, p^{\prime}-\mathrm{DDT}$ and of $o, p^{\prime}-\mathrm{DDT} / p, p^{\prime}-\mathrm{DDT}$ in Vhembe are unusually high. In view of the fact that it is only $p, p^{\prime}-\mathrm{DDT}$ that is effective against the malaria carrying mosquito, these unusual ratios suggest that the insecticidal efficacy of the active ingredient in commercial DDT IRS products used prior to and during the 2007 season were reduced. Additionally, technical DDT has oestrogen-like properties, mainly due to $o, p^{\prime}$-DDT [29] and therefore levels of $o, p^{\prime}$-DDT in IRS products higher than necessary are cause for concern. $0, p^{\prime}$-DDT and $o, p^{\prime}$-DDD are chiral molecules and both exist as enantiomeric pairs [26, 40]. o,p'-DDT exhibits enantioselective oestrogenicity $[39,41,42]$ and biodegradability $[26,40]$. (-)o,p'-DDT enantiomer is a weak oestrogen mimic while $(+) o, p^{\prime}-\mathrm{DDT}$ is inactive $[39,41,42]$. Airborne 
enantiomers of R(-)o, p'-DDT and S(+)o, p'-DDT and of S(+)o, p'-DDD and R(-)o,p'DDD were measured in indoor vapour and particle phases after IRS [40]. Two very different enantiomeric profiles were revealed: indoor air vapour phase displayed a racemic composition, while indoor airborne particulate phase displayed a nonracemic composition [40].

Regrettably, the commercial DDT product used during the IRS 2007 season was not made available to us for analysis. Commercial DDT products supplied to us in 2008 , and analysed by us, contained $\sim 73 \% p, p^{\prime}$-DDT relative to $\Sigma$ DDT with the balance consisting of mainly $0, p^{\prime}$-DDT and levels of DDD were within specification. However, the chromatogram showed the presence of, amongst others, a pyrethroid and organochlorine compounds other than the target compounds reported in this study. Quality control of IRS products should include a full inspection of the total chromatogram, and not only of $p, p^{\prime}$-DDT.

\subsection{Comparison of PUF and denuder (multi-channel PDMS trap + filter + multi- channel PDMS trap) samplers}

Indoor air of the huts was sampled concurrently by PUF and denuder (multichannel PDMS trap+filter+multi-channel PDMS trap) samplers directly after DDTspraying, after $4 \mathrm{~h}$ and after $24 \mathrm{~h}$ and the results are shown in Table 5. PUF was bulk solvent extracted and analysed by an external laboratory (Agricultural Research Council's Plant Protection Research Institute of South Africa (ARC-PPRI)) using GCECD. In general, a relatively good agreement between total (gas + particulate phases) $\Sigma$ DDT $\left(\mu \mathrm{g} \mathrm{m}^{-3}\right.$ ) for PUF and denuder device (multi-channel PDMS trap+filter+multi-channel PDMS trap) sampling was obtained. The relatively larger difference between PUF and denuder values obtained after $24 \mathrm{~h}$ is probably due to 
DDT spray drift from a larger number of huts sprayed within a $24 \mathrm{~h}$ period. Spray drift would also explain the elevated levels of $\Sigma$ DDT observed after $24 \mathrm{~h}$ for both PUF and denuder samplers. The total airborne concentrations were slightly higher in samples collected by denuder samplers than those collected by PUF (Table 5). This trend was also observed for atmospheric PAHs collected by diffusion denuder+filter vs. filter+PUF $[8,9,15]$

Because sample preparation steps are completely eliminated, the potential for loss of analyte and introduction of interferences are minimised with a denuder. In contrast, PUF requires solvent extraction followed by evaporation and clean-up which may cause loss of analytes and introduction of interferences and hence may result in lower values obtained with PUF. Disadvantages of PUF are that it is bulky, requires high volume sampling pumps which increases the potential for compound break-through, does not distinguish between vapour and particulate phases, and it requires solvent extraction, clean-up and concentration. In comparison, our denuder sampler distinguishes between vapour and particulate phases and uses compact, battery operated (an important consideration in rural areas), low volume sampling pumps. 
Table 5

Comparison of mean indoor air borne $\Sigma$ DDT $\left(\mu \mathrm{g} \mathrm{m}^{-3}\right)$ values obtained with PUF and a denuder (PDMS trap+filter+PDMS trap) sampler directly after indoor DDT-spraying $(0 \mathrm{~h}), 4 \mathrm{~h}$ and $24 \mathrm{~h}$ after IRS

\begin{tabular}{llccc}
\hline Interval & ${ }^{1}$ PUF & ${ }^{2}$ Denuder & ${ }^{2}$ Vapour Phase & ${ }^{2}$ Particulate Phase \\
\hline 0 & & PDMS trap+filter+PDMS trap & \\
4 & 11 & 13 & 10.6 & 2.9 \\
24 & 8 & 10 & 7.7 & 2.7 \\
\hline
\end{tabular}

${ }^{1}$ Bouwman et al. [28] ${ }^{2}$ Denuder device (multi-channel PDMS trap+filter+multi-channel PDMS trap) distinguishes between air borne vapour phase and air borne particulate phase, whilst PUF does not.

\section{Conclusions}

A new environmental forensic technique was developed for DDT IRS. Indoor air borne vapour phase and particulate phase $p, p^{\prime}$-DDT, $o, p^{\prime}-\mathrm{DDT}, p, p^{\prime}-\mathrm{DDD}, o, p^{\prime}-$ DDD, $p, p^{\prime}-\mathrm{DDE}$ and $o, p^{\prime}-\mathrm{DDE}$ were collected separately by a novel denuder multichannel PDMS trap+filter+multi-channel PDMS trap combination, at a low air flow sampling rate and a short collection time using a compact, battery operated field pump. The low cost denuder sampler is quick and simple to assemble and it fits commercial thermal desorbers. Solvent extraction of the sampling materials, extract clean-up and concentration are not required. Instead, solventless thermal desorption allows transfer of the entire sample mass to the CIS inlet of a GC-MS. CIS injection is mild compared to conventional isothermal GC injection, minimising the conversion of DDT to DDD during injection. LODs and LOQs of the GC-MS (SIM) EI+ mode method were at $\mathrm{ng} \mathrm{m}^{-3}$ levels for $4 \mathrm{~L}$ of air sampled. Vapour phase and particulate phase $p, p^{\prime}-\mathrm{DDT}, o, p^{\prime}-\mathrm{DDT}, p, p^{\prime}-\mathrm{DDD}, o, p^{\prime}-\mathrm{DDD}, p, p^{\prime}-\mathrm{DDE}$ and $o, p^{\prime}-\mathrm{DDE}$ were each quantified separately. Vapour phase mean $\Sigma$ DDT $3.82 \mu \mathrm{g} \mathrm{m}^{-3}$ and particulate phase 
mean $\Sigma$ DDT $1.52 \mu \mathrm{g} \mathrm{m}^{-3}$ were measured inside traditional huts prior to DDT spraying. Following a $24 \mathrm{~h}$ waiting period after DDT IRS vapour phase mean $\Sigma$ DDT was $12.37 \mathrm{\mu g} \mathrm{m}^{-3}$ and particulate phase mean $\Sigma$ DDT was $2.30 \mu \mathrm{g} \mathrm{m}^{-3}$. Ratios of airborne $p, p^{\prime}-\mathrm{DDD} / p, p^{\prime}-\mathrm{DDT}$ and of $o, p^{\prime}-\mathrm{DDT} / p, p^{\prime}-\mathrm{DDT}$ were unusually high and do not match the ideal ingredient composition required of certified commercial DDT. Our technique, gentler than conventional injection, reduces uncertainty as to the origin of the unusually high DDD values. Insecticidal efficacy of a DDT IRS product may have been compromised which may explain an incidence of malaria outbreaks following IRS. Since sampling was done under undisturbed conditions we cannot conclude that particulate phase insecticide presents an unimportant pathway for human exposure. Our method is well-suited for use in a follow up study involving the sampling of air during domestic activities (sweeping, dusting). The same sampling method also allows enantiomeric analysis at the concentrations indicated.

Enantiomeric analysis would eliminate uncertainties as to whether the fraction of DDD present in the environment is due to dubious IRS products or to the ageing of DDT. Our method is not limited to DDT, and can be used for air pollution monitoring of additional POPs and PAHs.

\section{Acknowledgements}

We are most grateful to Prof Riana Bornman of the Department of Urology, University of Pretoria, for her generous assistance in the collection of air samples during the 2007 IRS season, to Dr Fanie van der Walt for designing and building the portable sampling pumps, to Sasol and the National Research Foundation (NRF) for funding, to Rosy Ocwelwang for laboratory assistance during TDS and GC inlet degradation evaluation, Etienne van der Walt, Ephraim Bafane Malinga and Joel 
Matibisi Mooka (ARC-PPRI) for sampling of the indoor air of huts, Azel Swemmer of

FDA Laboratories for kindly providing commercial (technical) DDT formulations.

\section{References}

[1] World Malaria Report, World Health Organisation (2010) [online]. Available: http://www.who.int/malaria/publications/country-profiles/profile zaf en.pdf (Accessed 28.06.2011).

[2] World Malaria Report, World Health Organisation (2011) [online]. Available: http://who.int/malaria/world malaria report 2011/en/index.html (Accessed 31.01.2012).

[3] J. Volckens, D. Leith, Ann.occup. Hyg. 47(2) (2003)157-164.

[4] P. Larsson, O. Berglund, C. Backe, G. Bremle, A. Eklöv, C. Järnmark, A. Persson, Naturwissenschaften 82 (1995) 559-561.

[5] J.C. Van Dyk, H. Bouwman, I.E.J. Barnhoorn, M.S. Bornman, Sci. Total Environ. 408 (2010) 2745-2752.

[6] M. Millet, in: J.L. Tadeo (Ed.), Sampling and Analysis of Pesticides in the Atmosphere, CRC Press, Boca Raton, Florida, 2008, pp. 257-286.

[7] E. Borrás, P. Sánchez, A. Muñoz, L.A. Tortajada-Genaro, Anal. Chim. Acta (2010), in press, doi:10.1016/j.aca.2011.05.009.

[8] M. Possanzini, V. Di Palo, P. Gigliucci, M.C.T. Scianò, A. Cecinato, Atmos. Environ. 38 (2004) 1727-1734.

[9] M. Possanzini, V. Di Palo, G. Tagliacozzo, A. Cecinato, Polycycl. Aromat. Comp. 26(3) (2006) 185-195.

[10] A.J. Peters, D.A. Lane, L.A. Gundel, G.L. Northcott, K.C. Jones, Environ. Sci. Technol. 34 (2000) 5001-5006.

[11] D.E. Tobias, J.A. Perlinger, P.S. Morrow, P.V. Doskey, D.L. Perram, J. Chromatogr. A. 1140 (2007) 1-12.

[12] S.A. Batterman, S.M. Chernyak, Y. Gounden, M. Matooane, R.N. Naidoo, Sci. Total Environ. 397 (2008) 119-130.

[13] H. Alegria, T.FR. Bidleman, M. Salvador Figueroa, Environ. Pollut. 140 (2006) 483-491. 
[14] R. Barro, J. Regueiro, M. Llompart, C. Garcia-Jares, J. Chromatogr. A. 1216 (2009) 540-566.

[15] M. Goriaux, B. Jourdain, B. Temime, J.-L. Besombes, N. Marchand, A. Albinet, E. Leoz-Garziandia, H. Wortham, Environ. Sci. Technol. 40 (2006) 6398-6404.

[16] E. Baltussen, C.A. Cramers, P.J.F. Sandra, Anal. Bioanal. Chem. 373 (2002) 3-22.

[17] P. Bohlin, K.C. Jones, B. Strandberg, J.Environ.Monit. 9 (2007) 501-509.

[18] P.B.C. Forbes, E.R. Rohwer, Environ. Pollut. 157 (2009) 2529-2535.

[19] D.A. Lane, N.D. Johnson, S.C. Barton, G.H.S. Thomas, W.H. Schroeder, Environ. Sci. Technol. 22(8) (1988) 941-947.

[20] M.S. Kriegler, R.A. Hites, Environ. Sci. Technol. 26 (1992) 1551-1555.

[21] E.K. Ortner, E.R. Rohwer, J. High Res. Chromatog. 19 (1996) 339-343.

[22] P.B.C. Forbes, E.R. Rohwer, WIT Trans. Ecol. Envir. 116 (2008) 345-355.

[23] P.B.C Forbes, A. Trüe, E.R. Rohwer, Environ. Chem. Lett. 9 (2011) 7-12.

[24] P.B.C. Forbes, E.W. Karg, R. Zimmermann, E.R. Rohwer, The use of multichannel silicone rubber traps as denuders for polycyclic aromatic hydrocarbons, Anal. Chim. Acta (2011), doi:10.1016/j.aca.2011.11.013, in press.

[25] A.S.Y. Chau, B.K. Afghan, Analysis of Pesticides in Water. Significance, Principles, Techniques, and Chemistry of Pesticides, volume 1, CRC Press Inc., Boca Raton, Florida, 1982, p.11.

[26] J. Muñoz-Arnanz, C. Bosch, P. Fernandez, J.O. Grimalt, B. Jimenez, J. Chromatogr. A. 1216 (2009) 6141-6145.

[27] W.T. Foreman, P.M. Gates, Environ. Sci. Technol. 31(3) (1997) 905-910.

[28] H. Bouwman, R. Bornman, C. van Dyk, I. Barnhoorn, H. Kylin. Dynamics and risks of DDT applied indoors for malaria control. Poster presentation at the $12^{\text {th }}$ EuCheMS International Conference on Chemistry and the Environment, Stockholm, Sweden, 14-17 June 2009.

[29] R. Bornman, C. de Jager, Z. Worku, P. Farias, S. Reif, BJUI. (2009) 1-7.

[30] S. Hosie, S. Loff, K. Witt, K. Niessen, K.-L. Waag, Eur. J. Pediatr. Surg. 10 (2000) 304-309.

[31] H. Bouwman, B. Sereda, H.M. Meinhardt, Environ. Pollut. 144 (2006) $902-$ 917. 
[32] X. Qiu, T. Zhu, B. Yao, J. Hu, S. Hu, Environ. Sci. Technol. 39 (2005) 43854390 .

[33] Y. Naudé, W.H.J. de Beer, S. Jooste, L. van der Merwe, S.J. van Rensburg, Water SA. 24(3) (1998) 205-214.

[34] K.T. Lee, S. Tanabe, C.H. Koh, Environ. Pollut. 114 (2001) 207-213.

[35] T.O. Said, K.M. El Moselhy, A.A.M. Rashad, M.A. Shreadah, Bull. Environ. Contam. Toxicol. 81 (2008) 136-146.

[36] T. G. Negoita, A. Covaci, A. Gheorghe, P. Schepens, J.Environ.Monit. 5 (2003) 281-286.

[37] C. Herrera-Portugal, H. Ochoa, G. Franco-Sánchez, L. Yáñez, F. DíazBarriga, Environ. Res. 99 (2005) 158-163.

[38] S. De Francia, E. Pirro, F. Zappia, F. De Martino, A.E. Sprio, F.Daffara, M. Terzolo, A.Berruti, F. Di Carlo, F. Ghezzo, J. Chromatogr. B. 837 (2006) 6975.

[39] E. Eljarrat, P. Guerra, D.Barceló, Trends Anal. Chem. 27 (2008) 847-861.

[40] Y. Naudé, E.R. Rohwer, Two multidimensional chromatographic methods for enantiomeric analysis of $o, p^{\prime}$-DDT and $o, p^{\prime}$-DDD in contaminated soil and air in a malaria area of South Africa, Anal. Chim. Acta, (2012), doi:10.1016/j.aca.2012.03.028, in press.

[41] P.F. Hoekstra, B. K. Burnison, T. Neheli, D.C.G. Muir, Toxicol. Lett. 125 (2001) 75-78.

[42] X.-Z. Meng, Y. Guo, B.-I. Mai, E.Y. Zeng, J. Agric. Food Chem. 57 (2009) 4299-4304. 